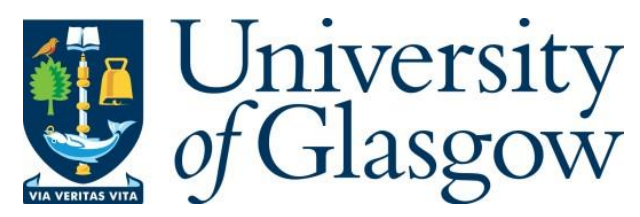

Brady, M. S. (2020) Pride and humility. In: Alfano, M., Lynch, M. P. and Tanesini, A. (eds.) The Routledge Handbook of Philosophy of Humility. Series: Routledge handbooks in philosophy. Routledge: Abingdon, Oxon ; New York, NY, pp. 106-116. ISBN 9780815364115.

There may be differences between this version and the published version. You are advised to consult the publisher's version if you wish to cite from it.

http://eprints.gla.ac.uk/243029/

Deposited on: 1 June 2021

Enlighten - Research publications by members of the University of Glasgow http://eprints.gla.ac.uk 


\title{
Pride and Humility
}

\author{
Michael S. Brady
}

Humility is held to be more valuable, more morally praiseworthy, than pride. Some make this point in terms of virtues - that humility counts as virtuous, whilst pride, if not a vice, fails to be a virtue. There are of course those who disagree with such a ranking - Aristotle is one notable example of someone who seems to have had an opposing assessment of the value of these states - but on the whole philosophers and common sense opinion converge in thinking better of those who are humble than they do of those who are proud. This raises a puzzle, however. For there are considerable similarities between pride and humility. Both, for instance, involve a relation to something that is good or valuable; both have an 'appraisal structure' that reflects this relation; and both function to communicate this relation to others, and so have an essentially social nature. Given this, those who think humility is virtuous whilst pride is not are faced with a problem - namely, the problem of explaining this difference in our aretaic rankings of them, by appealing to some other feature or condition that suffices to distinguish the two. In this paper I'll argue that a number of recent attempts to explain what humility is, and in so doing explain why humility is virtuous, fail on this account. In the final section, I'll suggest that a more plausible solution can be found if we locate the relevant difference in how these emotions are expressed, and in particular in the respective demands that such expressions make on us. We'll see that whereas the communication of pride requires us to make a particular response - to esteem and give deference to the proud person - 
the communication of humility permits, but does not require, such an attitude. Because of this, humility allows us to bestow gifts of esteem on the humble person, in a way which we find agreeable, but also in a way that itself expresses respect for our freedom. As a result, we not only find humility more agreeable than pride; it also seems to embody a more valuable (because more respectful) motive. Or so, at least, I'll argue.

\section{Preliminaries}

(i) We talk of pride and humility as episodes, and also as traits. Thus someone might experience feelings of pride in a particular instance - when she's receiving her degree certificate, say; and the same person might experience instances of humility or modesty - when she's asked afterwards about her achievement, for example. ${ }^{1}$ We also talk of humble or modest people, and mean by this those who are disposed to be humble or modest in the right circumstances. Things are a little more complicated when we talk of proud people - which might be one reason why the latter is often regarded as of dubious value. For calling someone a proud person seems to imply that they have an overly rigid, and perhaps exaggerated, view of their own standing and qualities. We sometimes say that people are too proud to do manual labour, or too proud to be seen in that pub or with those people, or too proud for their own good, and so on. Our puzzle would easily be solved if we pointed out the difference between the modest person, and someone who is proud in this kind of way. But the puzzle remains, I think, when we focus on episodes of pride and humility. To avoid complications associated with pride as a (potentially dubious) long-standing character trait, therefore, I'll 
focus on the former: cases where, for instance, a tennis player is proud of his victory, or a musician is humble or modest about her performance.

(ii) Pride and humility are, in the episodic sense, emotions. We talk easily of feelings of pride, and equally of feeling humble(d), and so the episodes have associated affective elements. ${ }^{2}$ As we'll see, pride and humility have a particular appraisal structure: they involve evaluations of the world and of oneself, they embody ways of seeing or perceiving value. Pride and humility have effects on attention and other cognitions. They incline us towards certain behaviours. And they have associated facial and bodily expressions. Since emotions are standardly characterized just in terms of this collection or elements or components, it is plausible to think that pride and humility are also emotional. ${ }^{3}$

(iii) Pride and humility need to be distinguished from their respective close relations. Pride should be distinguished from arrogance (which is associated with being unpleasantly or overbearingly proud) and self-aggrandizement (which is associated with aggressively promoting one's own power and accomplishments). Again, it would be too easy a solution to our puzzle to castigate pride by aligning it with one of these vices. But if one is tempted by this argumentative line, note that we can do the same with humility: for we can equally well distinguish humility from timidity (which is associated a lack of courage or confidence) and self-deprecation (which is associated with belittling and disparaging oneself). These too are vices, but it is no strike against humility that it can be mistakenly associated with such things. 
With these preliminaries in mind, let us outline the nature of pride and humility, and highlight the important similarities between them, similarities which generate the problem of distinguishing them in terms of their value.

\section{Similarities between pride and humility}

There are many different accounts of pride. But what most have in common is a certain 'appraisal structure'. Roughly, pride involves an appraisal or assessment of an object or event as (i) valuable, and (ii) as related in some way to oneself. A prominent and plausible account of pride is due to Gabriele Taylor, who writes:

"[A] person who experiences pride believes that she stands in the relation of belonging to some object (person, deed, state) which she thinks desirable in some respect. This is the general description of the explanatory beliefs. It is because (in her view) this relation holds between her and the desirable object that she believes her worth to be increased, in the relevant respect. This belief is constitutive of the feeling of pride. The gap between the explanatory and identificatory beliefs is bridged by the belief that her connection to the thing in question is itself of value, or is an achievement of hers." 4

On this view, there are three 'conditions' for pride. First, pride is dependent: we feel pride as a response to some object or event that, in our eyes at least, constitutes a positive value. Second, we must regard the valuable object or event as standing in some relation to us. As Jeremy Fisher puts it, "experiencing the emotion of pride requires that we view ourselves as standing in some special relation to the object of our emotion." ${ }^{5}$ In Taylor's terms, this relation can be a 
broad one, such as 'belonging'. Taylor writes: "It is in virtue of belonging to the same family, the same country or institution that people are proud of their ancestors, countrymen, or colleagues." 6 Third - and this will be important as we go on - the proud person must regard her standing in this relation as something that is itself valuable, as a source of self-worth or esteem. It is not simply the fact that one stands in a relation of belonging to something of value that suffices for pride; I might, after all, not feel pride about my family's mansion, despite its value and my relation to it, since I regard such ostentatious displays of wealth to be immoral. The proud person must therefore regard the fact that she is in a relation with something of value as bearing positively on her worth. Together, these three beliefs - or perhaps cognitions that fall short of beliefs - make up the complex appraisal that is distinctive of pride, and without these three beliefs our feeling would fail to be an instance or episode of pride. What, then, of humility? As with pride, there are a variety of different accounts of humility. We'll see some recent accounts shortly. What (nearly) all accounts of humility seem to have in common is something noted by Michael Slote, namely that humility is also dependent upon some other good, and so, like pride, is a relational state. As Nicolas Bommarito puts it, "being modest requires some other good quality for us to be modest about."7 We might capture this dependent or relational aspect of modesty by proposing that it too has a particular appraisal structure. Humility, like pride, must involve thinking or believing that one stands in a relation to some good or value. As with pride, the good or value might not be something that the person themselves has brought about. People are often humble or modest about their own qualities and achievements, but this need not be the case: I can be modest about the achievements of my children, or the prestige of my 
university. This means that the first two conditions for pride are mirrored for humility: we feel humility in relation to some valuable object or event or quality, and we regard the object (etc.) as standing in some relation to us. Following Taylor, we might think that this is once again a relation of 'belonging'. To this point, then, we've not encountered any real difference between pride and modesty, at least at the level of appraisal structure. Both involve thinking about the relation between oneself and something of value in a particular way.

What of the third condition? Do pride and humility differ here? Some might be tempted to think so, and maintain that whereas pride requires the thought or belief that the relation in question bears positively on one's standing, humility doesn't involve any such appraisal. Indeed, some might go further and claim that humility cannot involve thinking of the relation in this way: that it is a necessary condition on being modest or humble that one does not have this belief. This would be a version of an 'ignorance' account of the concept. As Bommarito states, such accounts "explain modesty by appeal to states that are epistemically defective in some way; the modest person either lacks certain beliefs about their own goodness or has false beliefs that involve underrating themselves." 8 So on this view, the modest person must be ignorant of the fact that her standing in a relation to something of value speaks well of her, enhances her standing in the eyes of others.

There are a couple of problems with this line, however. First, it seems unduly restrictive: there seems little reason, other than adherence to the theory, to suppose that the modest person cannot have a belief about of how the relation in question enhances her standing. Consider: it is at least possible (indeed, reasonably likely, given how he conducts himself in interviews) that Andy 
Murray is a modest person. But he is surely aware of how his tennis prowess and achievements are viewed by his fellow Scots. Modesty surely cannot require Andy Murray to be puzzled when he keeps winning awards and public acclaim, for instance. Second, it is not at all obvious how lacking the belief in question makes the modest person better or more virtuous than someone who is proud of his achievements, and so who is aware of how the relation bears positively on his standing. Whatever the reason we prefer those who are modest to those who are proud, clearly lack of the relevant belief isn't it. If so, it's plausible to suppose that pride and modesty have the same kind of appraisal structure, at least to the extent that they share the three 'conditions' explained above. How, then, might we explain the difference in the evaluative status that pride and humility have? In the next section, I'll examine some recent ways of answering this question, and argue that none of them are convincing.

\section{Modesty as hedonic indifference, kindness, and inattention}

Suppose we move away from 'doxastic' accounts, which focus on some putative epistemic difference between the states, and look to some non-doxastic element to solve our puzzle. In this section I'll examine accounts which appeal to differences in pleasure, kindness, and attention, in attempting to show why humility, but not pride, counts as virtuous.

(i) Even if pride and humility share a certain appraisal structure, one rather obvious difference between them is at the level of hedonics. This is because pride would seem to involve a subject's taking pleasure in the fact that the relevant 
relation bears positively on their standing, whilst the humble subject does not. In support of the former, note that the typical facial expression of pride is one in which the subject seems pleased with herself and her achievement. ${ }^{9}$ Pride and pleasure seem very closely linked, therefore. Not so with humility, which some want to characterize in terms of a lack of any pleasure. Indeed, a number of accounts of humility highlight precisely that it involves an indifference to the fact that one's relation to some good bears positively on one's standing. ${ }^{10}$ On this account, it is the fact that one fails to take pleasure in the relevant fact that makes the person virtuous; conversely, those who are proud fail to be virtuous precisely because they take pleasure in the fact of their relation to some good. Does this solve our puzzle? Not really. For one thing, the pleasure that pride involves is often entirely fitting from a moral perspective. Suppose that Lucy has just been made captain of the school football team; Lucy, and others, would expect Lucy's parents to be beaming with pride at this achievement. This is not just an expectation, reflective of how parents tend to react in cases like this. There would be something morally and normatively amiss if Lucy's parents didn't take pleasure in this fact. So taking pleasure in achievement that is suitably related to one cannot be the reason why we think pride isn't virtuous. Indeed, there is theoretical backing for this intuitive take on Lucy's situation. Consider Thomas Hurka's work on the nature of virtue. In his book Virtue, Vice, and Value, Hurka proposes and defends a 'recursive characterization' of good and evil.11 This characterization involves a number of clauses. For our purposes, two are particularly important. The first is a recursion clause "about the intrinsic goodness of a certain attitude to what is good, namely, loving it, or, more specifically, loving for itself what is good, (LG): If $\mathrm{x}$ is intrinsically good, loving $\mathrm{x}$ 
(desiring, pursuing, or taking pleasure in $\mathrm{x}$ ) for itself is also intrinsically good."12 He supplements this with a clause about indifference to goods: "(IG) If $\mathrm{x}$ is intrinsically good, being indifferent to $\mathrm{x}$ (neither loving nor hating $\mathrm{x}$ when, given one's cognitive states, one could do so) for itself is intrinsically evil."13 Hurka claims, further, that "The moral virtues are those attitudes to goods and evils that are intrinsically good, and the moral vices are those attitudes to goods and evils that are intrinsically evil." 14 On this view, then, it is virtuous to take pleasure in something that is good, and vicious to be indifferent to something that is good. On the assumption that enhancement in social standing is a good, it would follow from Hurka's recursive account that pride is virtuous precisely on the grounds that it involves pleasure.

Hurka is not alone in taking virtue to be a way of favouring what is good. Robert Adams holds something similar, claiming: "I identify virtue with persisting excellence in being for the good."15 Linda Zagzebski also holds that virtues involve positive attitudes towards goods and negative attitudes towards evils, embodied in the emotional responses that constitute the 'motivational components' of virtue. ${ }^{16}$ Indeed, virtue theorists in general - no doubt influenced by Aristotle to some extent - deny that taking pleasure in (virtuous) activity in any sense undermines the virtue-status of that activity. If so, it is difficult to see how pride falls short of virtue on hedonic grounds. The appeal to pleasure as a differentiating element fails to answer our puzzle, therefore.

(ii) A different approach appeals, not to pleasure, but to kindness. Consider, in this light, Alan Wilson's 2014 paper 'Modesty as Kindness'. ${ }^{17}$ Wilson thinks that accounts of modesty which restrict themselves to 'features internal to an 
agent', ${ }^{18}$ such as beliefs about their own abilities or comparisons with others, allow 'for the agent to be both proud and obnoxiously boastful about some ability that they possess. ${ }^{19}$ For Wilson, 'What is needed is an external requirement - a restriction of how the truly modest agent will behave in their interactions with other people.' (Ibid.) Wilson's own requirement invokes kindness. He writes: 'My suggestion is that the trait of modesty ought to be considered as closely related to the more fundamental virtue of kindness. It is at least part of the nature of kindness that the kind agent will be concerned to protect and promote the well-being of others. The modest agent is one who shares this concern and who is influenced by it in the way that they present themselves. ... To be modest is to be disposed to present your accomplishments/positive attributes in a way that is sensitive to the potential negative impact on the well-being of others, where this disposition stems from a concern for that well-being.'20

Wilson thinks that this allows us to explain why modesty is virtuous. Part of the explanation here is that the modest person, being kind, will be concerned not to undermine the esteem of others, and so will avoid 'bragging and boasting about their achievements'. As a result, the humble person 'is unlikely to provoke envy and dislike in others', and so will maintain cordial social relations. Since this is a good end, then modesty will be reliably connected with this end. But the main reason for viewing modesty in a positive light is because of a close relation to an overarching virtue. Wilson writes: 'The modest agent is concerned to protect and promote the well-being of others through their self-preservation, and so will be likely to also possess the virtue of kindness. ${ }^{21}$ This helps us to explain the value of episodes of modesty as well, in so far as particular instances 
of modesty will express the feelings that the kind and hence virtuous person is disposed to have. Episodes of modesty count as virtuous for this reason.

There is a lot that is attractive about Wilson's account. Unfortunately, it suffers from a couple of problems. First, it seems to be too narrow in its focus on the potential negative impact on the well-being of others. Consider Andy Murray again. I take it that Andy can be modest when he is motivated to downplay his impressiveness, even in situations where there is little or no chance of negative impact on the well-being of others. Suppose, for instance, he is at a dinner celebrating Grand Slam winners since 2010. Surely it's possible for him to be modest, and yet rightly unconcerned with the effect that his talking about his accomplishments might have on the well-being of Serena Williams and Novak Djokovic. So his motivation to downplay his achievements here cannot be kindness to them.

Second, and importantly, the appeal to kindness doesn't really help us to solve our puzzle. This is because pride can equally fit Wilson's definition: the proud person can also be disposed to present her accomplishments or positive attributes in a way that is sensitive to the potential impact on the well-being of others, where this disposition stems from a concern for that well-being. For the proud person might sometimes be disposed to display pride because of the positive impact this will have on the well-being of others: think again of Lucy's proud parents being sensitive to the benefit such an emotional expression brings to their daughter, or sensitive to the harm that their failure to express pride in Lucy's achievements might cause. This point is not simply restricted to cases where someone is proud of a family member or another in a relation of 'belonging'. Olympic athletes on the winners' podium might rightly display pride 
out of sensitivity to the sacrifices that their trainers have made, or the financial support of their funding bodies, or the applause and adulation of the crowd and indeed the nation. (Failure to display pride in such cases would be evidence of mean-spiritedness or a lack of public concern, a kind of churlishness.) A disposition to feel pride, no less than modesty, can therefore express kindness and a sensitivity to the well-being of others. As a result, an appeal to kindness gets us no further to solving our puzzle.

(iii) A third recent approach, due to Nicolas Bommarito, grounds the value of modesty in 'certain patterns of attention'. ${ }^{22}$ Like Wilson, Bommarito thinks that 'a good theory will ... provide a framework that helps us see what is good about modesty and what is bad about immodesty'. ${ }^{23}$ He thinks that 'what is essential to modesty is that we direct our attention in certain ways', and that as a result modesty is a virtue of attention. ${ }^{24}$ In particular, he claims that the modest person will direct her attention 'away from the trait or its value or toward the outside causes and conditions that played a role in developing it.'25 So a modest person might not attend to the fact that she is a skillful driver, or to the value of her architectural work; or she might instead focus on the vital role that others have played in enabling her to fulfil her talent and achieve what she does. But these patterns of attention are not sufficient for modesty; instead, the modest person's attention must be directed in one of these ways 'for the right reasons ... [as] a result of their values or desires.' (Ibid.) In the case of someone who attends to external factors and their role in enabling her to exhibit her skill, attention is governed by her concern for the importance of family, friends, and society; so her attention seems virtuous as a result. By the same token, someone might be 
inattentive to her abilities, or to the value of these, because she lacks certain morally problematic (e.g. narcissistic) desires or concerns. It is the absence of negative values or desires that makes inattention in these cases virtuous. And it is this feature which also helps to explain why modesty is a virtue: namely, that it manifests morally good or valuable desires and concerns, or a lack of morally bad desires. Immodesty, on the other hands, expresses and manifests 'egocentric vices', and as such counts as morally criticizable. ${ }^{26}$

This too is a rich and initially attractive account of the nature of modesty and of its value. However, it is problematic for much the same reason as Wilson's - namely, it doesn't do enough to distinguish (the value of) modesty from pride, and so fails to address our puzzle. Modesty and pride might very well differ in terms of their patterns of attention - with the proud person being more attentive to their own qualities or the value of these qualities than the modest person, and less attentive to the role that external factors have played with respect to the value in question. But none of these differences need evince morally problematic desires or concerns on the part of the proud person. Indeed, the case can be made that dispositions to feel pride in one's abilities can reliably express virtuous dispositions themselves. The proud Olympian might reliably attend to her abilities and their value because she thinks that inattention to her talents would be neglectful or sinful: she pays attention to them and to their value because she regards them as a gift, and, as with other gifts, attention (rather than inattention) seems apt as a form of gratitude. By the same token, she might be less attentive to the role that external factors have played with respect to her achievements precisely because external factors have had little to do with her success. Instead, any external factors she has faced have been ones that she has 
had to overcome: poverty, lack of parental support, indifference of funding bodies, the sexist or racist attitudes of the selection committees and fans and broadcasters, the jealousy of her team-mates; and so on. The notion, therefore, that relative inattention to help from others belies a morally problematic attitude would seem to be unfounded. Indeed, it might even be the case that those who are inclined to pay attention to the help they received from others are often more privileged than those who are not, precisely because the latter group of people didn't receive much help in the first place. It is not obvious, therefore, that paying attention to the help one received from others manifests a morally better attitude than paying attention to one's own abilities and the value of one's own achievements. It is therefore not clear why modesty is a virtue of attention whilst pride is not.

The lesson to be learnt from this discussion is that attempts to explain the difference in value between pride and humility that focus solely on the features of the subjects involved - whether doxastic elements like beliefs (inaccurate or accurate), hedonic elements like pleasure (or indifference), or virtues associated with kindness and attention - seem to fail. If we are to answer our puzzle, we should look elsewhere. In the final section, I'll make the case that we should shift focus to the reactions of others to those who display pride and humility. I'll suggest that those who are proud are less highly regarded than those who are humble, because pride requires or demands esteem from us, whilst humility makes esteem a gift that we can bestow. This is the case even if pride and humility each express or manifest virtues associated with kindness or attention. 


\section{Pride as demanding, humility as permissive}

We can better answer our question if we turn our attention away from what pride and humility are, and focus instead on what pride and humility $d o$. In short, I want to argue that pride signals that one merits esteem and a raised social standing, in such a way that these are demanded or required from others. Humility, conversely, does not. This is because the humble person's lack of concern with their enhanced public standing allows or permits the observer to be equally unconcerned. For if the humble person doesn't care about being esteemed, then it's difficult to see how esteeming her is required of others. Nevertheless, humility allows the observer to give a gift of esteem - to do something that isn't required, but expresses generosity on the observer's part. The basic thought is that we prefer expressions of humility to expressions of pride because the former allow us to be better, because more generous, people. Moreover, in allowing us to give the gift of esteem, humility also seems to express a valuable and virtuous motive - a form of respect, precisely for our freedom - and one that isn't expressed by pride, which demands our esteem. As a result, we don't just find humility more agreeable; it arguably embodies a more valuable and more virtuous motive.

To see this line in more detail, let's look at a recent and plausible socialfunctionalist account of pride developed in a paper from 2010 by Jessica Tracy, Azim Shariff, and Joey Cheng. ${ }^{27}$ On their account, 'pride is a psychologically important and evolutionarily adaptive emotion' that has 'evolved to serve specifically social functions' ${ }^{28}$ In particular, they argue that pride has evolved 'to help individuals transform culturally valued achievements into higher social 
status.' ${ }^{29}$ Tracy and her colleagues note that pride enhances status through 'its universally recognized nonverbal expression, which may function to inform observers (other social group members) of the proud individual's achievement, indicating that he/she deserves higher status' ${ }^{30}$. Recall here the facial and bodily expression of pride in the photograph of Tracy above. The authors support this with their own research: 'Using the Implicit Association Test ... we found that the pride expression is rapidly and automatically perceived as a signal of high status'. ${ }^{31}$ Such signals can be of value to the subject displaying pride, and thus who is perceived to be of high status as a result, since they then 'receive increased resources, attention, and other status-related benefits'. ${ }^{32}$ But such signalling and display can also benefit observers: those who observe the highstatus subjects can then 'more effectively navigate the status hierarchy by showing appropriate deference, knowing whom to emulate, forming productive alliances, and facilitating their own status jockeying'. ${ }^{33}$ So there is practical pressure for us to automatically show deference to those who display pride. Of course, we might ultimately come to reject these automatic impulses; we might, for instance, reflectively reject the idea that the proud person merits esteem (perhaps they are basking in reflected glory), and/or decide not to show deference to such people. Our quick and automatic perceptions of our evaluative landscape might prove to be inaccurate, and our quick and automatic tendencies to esteem others and show deference might turn out to be unfounded.

Nevertheless, it is not implausible to suppose that pride expressions instinctively call for a way of seeing the proud person - namely, as one who has high status and equally a behavioural response to the proud person - namely, of esteeming 
and showing appropriate deference to them. Such evaluative and behavioural responses are, at least prima facie, demanded or required of us.

It is plausible to think that humility can also play an important social role, via its facial and bodily expression. For there seem to be standard facial and bodily expressions associated with humility or modesty too: lowered gaze, turning away, blushing. ${ }^{34}$ And it might be argued that humility counts as virtuous as a result of these facial and bodily manifestations. As Bommarito notes, humility is sometimes regarded as virtuous in 'combating jealousy and making social interactions run more smoothly'. ${ }^{35}$ Whatever such things signal, it isn't primarily that the person is associated with some achievement; nor are such expressions automatically taken to be a mark of high esteem and enhanced social standing. One reason for this is that similar expressions are associated, not with achievements, but certain forms of failure: those associated with shame, guilt, and embarrassment, for instance. As a result, facial and bodily expressions associated with modesty don't seem to call for any particular response; at least, they don't call for or demand the kind of evaluative and behavioural responses as those automatically elicited by pride expressions.

If this is the case, then we can explain the difference in the aretaic status of humility and pride by appealing, not to anything central to the evaluative structure of these emotions, nor to differences in their valence or effects on attention, but instead to a difference in what expressions of these emotions demand of us as observers. For if the above is correct, pride expressions call for particular appraisals, viz. that someone merits esteem, and particular actions, viz. of esteeming that person. As noted, such requirements are only prima facie: they can be overridden by other considerations, and undermined if it turns out 
that the person isn't suitably related to something of value or worth. But they are requirements nonetheless. As a result, observing someone displaying pride has mandatory costs, in terms of appraising someone as having higher standing, and in showing due deference to them. And the fact that paying these costs can nevertheless benefit us doesn't mean that they are not demanded from us. The same is true of moral requirements, after all: although we benefit in the long run if we abide by the demands of morality, they are still demands.

Things are different when it comes to humility. Expressions of humility call for neither appraisals nor behaviour on the part of the observer. Although humility requires a relation to something of value, and although we might recognize the relevant facial and bodily expressions for what they are, humility doesn't demand that anyone actually esteem the humble person in light of this relation, or show due deference to them. To see this, note that if the modest person seems indifferent to or inattentive to her success or achievement - if she doesn't seem to take pleasure in this, but lowers her gaze and turns away, directs conversation elsewhere or to the achievements of others, as per the accounts of emotion explained earlier - then it is clear that we are permitted to do likewise. Consider: if your neighbour, glowing with pride, shows you pictures of his grandchildren, then there is some normative pressure on you to respond appropriately. Even if you don't think that they are the most adorable children on the planet, you are required to make the right kind of noises in response. Failure to do so would be at best rude, but more plausibly unkind. If, on the other hand, your neighbour never draws your attention to valuable objects to which he's related - grandchildren, new car, holiday in Cuba - then it seems that you are under no normative pressure to esteem him for such relations, nor show any 
deference to him on this account. 'If he doesn't care about these things', you might well say to yourself, 'then I'm not required to'. Humility, unlike pride, doesn't therefore demand or require some normative response.

This doesn't mean that such a response wouldn't in fact be appropriate or fitting; if someone is related to some valuable object, and if this isn't (say) a source of shame to them, then it seems perfectly acceptable to mention this fact, to esteem them for it, and to show due deference to them as a result. Although such responses are not required, they therefore seem permissible. This means that if we do esteem or show deference to the humble person, it is something in our gift, rather than a cost that is demanded from us. There might be many reasons why we would want to esteem the humble person: as an expression of gratitude, perhaps, or because (in the case of public acknowledgement) we think it important that others are aware of the humble person's achievements, or because such esteem and deference accurately reflects their social standing. Because of this, esteeming the modest or humble person is something that it is entirely fitting and appropriate to do. But this is something that humility allows us the freedom to do.

This helps to explain why we are inclined to value expressions of pride and humility differently - and why, as a result, we might think that the latter express a virtuous motive whilst the former do not. We find expressions of humility much more agreeable than pride because they allow us the freedom to act in an appropriate way, rather than demanding this from us: they allow us to make a gift of esteeming and showing deference to another person. But because such expression gives us the freedom to esteem and show deference to another, we might think that humility also expresses a measure of respect for us: respect 
for our capacity to freely show esteem, to freely render unto others what they are due. So expressions of humility both allow us the freedom to esteem others, and thus strike us as more agreeable than expressions of pride; at the same sime, they express respect for our capacity to do esteem others, and thus strike us as expressing virtuous motives. It is not kindness that humility and modesty express, therefore, but respect for the freedom of others to show esteem and deference as they wish. And whilst pride can, as we saw, express kindness, pride nevertheless demands that others esteem or show deference to us, and so does not itself express respect for the capacity of others to give us the gift of esteem. As a result, expressions of pride strike us as less worthy or less valuable motives, because they fail to express respect for our freedom in this way.

We started with a puzzle - to explain the difference in our aretaic assessments of pride and humillity. If I'm right, this puzzle can best be solved by reflecting on what pride and humility demand, or permit, us to do. This helps us to explain a difference in how agreeable we find these expressions and traits, and so helps to explain the difference in ranking along Humean lines. But it also helps to explain a difference in the value of the attitudes expressed themselves: humility expresses respect for our freedom to esteem, in a way that pride does not. Because of this, we are inclined to think that the motives expressed in humility are more valuable, and more virtuous, than those expressed in pride.

University of Glasgow 


\section{Bibliography}

Adams, R. (2006), A Theory of Virtue, Oxford: Oxford University Press

Bommarito, N. (2013), 'Modesty as a Virtue of Attention', Philosophical Review (2013), 122(1), 93-117.

Bommarito, N. (2018), 'Modesty and Humility', The Stanford Encyclopedia of Philosophy (Winter 2018 Edition), Edward N. Zalta (ed.), URL = <https://plato.stanford.edu/archives/win2018/entries/modestyhumility/>.

Darwin, C. (1890/2009), The Expression of the Emotions in Man and Animals, Cambridge: Cambridge University Press

Fisher, J. (2017), 'Pride and Moral Responsibility', Ratio 30(2): 181-96.

Hurka, T. (2001), Virtue, Vice, and Value, Oxford: Oxford University Press

Roberts, Robert, and Jay Wood, 2003, "Humility and Epistemic Goods" in M. DePaul and L. Zagzebski (eds.), Intellectual Virtue: Perspectives from Ethics and Epistemology, Oxford: Clarendon Press

Taylor, G. (1985), Pride, Shame, and Guilt: Emotions of Self-Assessment, New York: Oxford University Press

Tracy, J., Shariff, A. \& Cheng, J. (2010), 'A Naturalist's View of Pride', Emotion Review 2(2): 163-177

Tracy, J. L., Robins, R. W., \& Schriber, R. A. (2009), 'Development of a FACSverified set of basic and self-conscious emotion expressions', Emotion, 9, 554-559.

Wilson, Alan T., 2014, “Modesty as Kindness”, Ratio, 29(1): 73-88

Zagzebski, L. (1996), Virtues of the Mind, Cambridge, UK: Cambridge University Press 
${ }^{1}$ I will, throughout, treat humility and modesty as referring to the same kind of quality. This is, I take it, in line with what most philosophers think about this issue, although there are some dissenters. For this paper, I'll go with the majority view. It's not obvious that anything of importance rests upon this issue, given the arguments to come.

${ }^{2}$ Alessandra Tanesini suggested to me that it's doubtful whether we can feel humble, as opposed to feel humbled - by one's situation, by nature, by some other person's

qualities or performance, etc. I'm not so sure that we can't feel humble, however. I might enter the my boss's office feeling humble, in a situation when I'm going to ask for a raise, without it being true of me that I'm feeling humbled by the situation. (I might, after all, think it likely that I'll get the raise I'm asking for.) So too in cases where I've achieved something great - I can feel humble without feeling humbled in such situations.

${ }^{3}$ Many contemporary philosophers and psychologists regard emotions as clusters of components. For more on this, see Prinz, J. (2004), Ch. 1.

4 Taylor, G. (1985), Pride, Shame, and Guilt: Emotions of Self-Assessment, New York:

Oxford University Press, p. 41.

5 Fisher, J. (2017), 'Pride and Moral Responsibility', Ratio 30(2), p. 182

6 Taylor, G (1985), p. 30

7 Bommarito, N. (2013), 'Modesty as a Virtue of Attention', Philosophical Review 122(1), p. 94

8 Bommarito, N. (2018)

${ }^{9}$ See Tracy, J. L., Robins, R. W., \& Schriber, R. A. (2009). Development of a FACS-verified set of basic and self-conscious emotion expressions. Emotion, 9, 554-559.

${ }^{10}$ For this line, see Roberts, R., \& Wood, J. (2003), 'Humility and Epistemic Goods', in M. DePaul and L. Zagzebski (eds.), Intellectual Virtue: Perspectives from Ethics and

Epistemology, Oxford: Clarendon Press

11 Oxford University Press (2001).

${ }^{12}$ p. 13

13 p. 63

${ }^{14}$ p. 20

15 Adams, R. (2006), A Theory of Virtue, Oxford: Oxford University Press, p. 11.

16 Zagzebski, L. (1996), Virtues of the Mind, Cambridge, UK: Cambridge University Press

17 Wilson, Alan T., 2014, "Modesty as Kindness", Ratio, 29(1): 73-88

${ }^{18}$ p. 76

19 p. 77

20 p. 78.

21 p. $78-9$

22 'Modesty as a Virtue of Attention', Philosophical Review (2013), 122(1), p. 93.

23 p. 95.

${ }^{24}$ p. 99.

25 p. 103.

26 p. 115

27 Tracy, J., Shariff, A. \& Cheng, J. (2010), 'A Naturalist's View of Pride', Emotion Review 2(2): 163-177.

${ }^{28}$ p. 164

29 p. 168

30 p. 169

31 Ibid.

32 Ibid.

33 pp. $169-70$

34 See Darwin, C. (1890/2009), The Expression of the Emotions in Man and Animals, Cambridge: Cambridge University Press, p. 353-4. 
35 Bommarito, N. 'Modesty and Humility', The Stanford Encyclopedia of Philosophy (Winter 2018 Edition). 